\title{
ANALISIS KANDUNGAN PEMANIS BUATAN PADA SARI BUAH MARKISA PRODUKSI MAKASSAR
}

\author{
Ika Amilah Citra Tahir, Vitrianty \\ Fakultas Farmasi Universitas Muslim Indonesia \\ Email : ikhaamilahcitra@yahoo.co.id
}

\begin{abstract}
An investigation on analyse of artificial sweeteners saccharin and cyclamate content has been done in Markisa essence beverage production in Makassar. The aim was to determinet the quantity of the sweeteners contained in the beverages. Four branded of the beverages that has been taken from several Supermakets in Makassra as the sample's. quantitative analyse has done by spesific reagent mean while quantitative analyse by means of UV-Visible Spectrofotometry upon saccharin and Gravimetry method upon cyclamate. Result on quantitative test shown that these four sample's containing these two artificial sweetenes. Quantitative test upon these four samples the concentration of saccharin was mero than the concetration that estabilished bt the departement of health and for cyclamate was met the requirement by the departement.
\end{abstract}

Key words : Saccharin, Cyclamate, Markisa Essence Beverages Production, Makassar.

\section{PENDAHULUAN}

Untuk mempertahankan sari buah markisa agar tetap awet selama penyimpanan dalam jangka lama dan untuk menjaga aroma serta cita rasanya, maka sari buah tersebut sering dipekatkan. Disamping itu, biasanya ditambahkan bahan tambahan seperti pengawet, pemanis dan lain sebagainya (Apriyantono, 1989).

Pemanis buatan adalah bahan tambahan makanan yang dapat menyebabkan rasa manis pada makanan yang tidak atau hampir tidak mempunyai nilai gizi. Oleh karena itu, digunakan oleh mereka yang membatasi konsumsi gulanya atau oleh pasien diabetes mellitus. Tetapi karena harganya relatif murah dari gula maka sering digunakan oleh pedagang dalam produk-produknya. Salah satu diantaranya adalah dalam pembuatan Sari Buah Markisa di mana Sari Buah ini telah banyak di konsumsi oleh masyarakat luas utamanya masyarakat di Sulawesi Selatan (Winarno, 1992). Pemanis 
buatan yang banyak digunakan di Indonesia adalah Sakarin dan Siklamat. Beberapa penelitian terhadap hewan pecobaan menunjukkan bahwa Sakarin dan Siklamat bersifat karsiogenik yang dapat menyebabkan timbulnya kanker, sehingga penambahan pemanis buatan dalam makanan dan minuman selalu diatur dalam surat keputusan Pejabat/Pemerintah yang berwenang melalui Menteri Kesehatan RI No. 722/MenKes/Per/IX/1988 tentang Pemanis Buatan. Penggunaan Sakarin yang di izinkan adalah $50-300 \mathrm{mg} / \mathrm{kg}$ bahan dan Siklamat adalah $500 \mathrm{gr}-3$ $\mathrm{g} / \mathrm{kg}$ bahan (Sunita. 2003, Syafri. 1997).

\section{METODE PENELITIAN}

\section{Alat dan Bahan}

Alat yang digunakan Cawan porselin. Corong pisah, Eksikator. Gelas Erlenmeyer. Gelas ukur, Gelas arloji, Kertas saring biasa, Kertas saring Whatman 42, Labu tenkukur, Pipet volum, Pengaduk kaca, Penangas air, Spektrofotometri UV.Visibel, Timbangan analitik, Tanur.

Bahan yang Digunakan Air suling, Eter, Larutan $\mathrm{HCl} 10 \%$, Larutan $\mathrm{H}_{2} \mathrm{SO}_{4}$ pekat, Larutan $\mathrm{NaOH}$ $10 \%$, Larutan $\mathrm{NaOH} 0,1 \mathrm{~N}$, Larutan $\mathrm{BaCl}_{2} 10 \%$, Larutan $\mathrm{NaNO}_{2} 10 \%$,
Resolsinol p.a, Sakarin p.a, Sampel Sari Buah Markisa

\section{Prosedur Kerja}

\section{Pengambilan Sampel}

Sampel Sari Buah Markisa Produksi lokal diambil dari beberapa Supermaket di Makassar secara acak dari ke empat sampel yang dipilih sampel $A$, sampel $B$, sampel $C$, dan sampel D Produksi Makassar.

\section{Pengolahan Sampel}

Sampel yang akan dianalisis dimasukkan ke dalam gelas piala lalu ditambahkan air suling secukupnya kemudian diaduk hingga homogen dan disaring dengan menggunakan kertas saring.

\section{Analisis Kualitatif}

\section{Analisis Kualitatif Sakarin dengan Uji Resorsinol}

Sampel dimasukkan ke dalam corong pisah dan diasamkan dengan 10 tetes $\mathrm{HCl} 10 \%$, dan diekstraksi dengan $25 \mathrm{ml}$ eter sebanyak 3 kali. Ekstrak eter dikumpulkan dan di uapkan dalam tabung reaksi di udara terbuka hingga kering. Tambahkan 10 tetes $\mathrm{H}_{2} \mathrm{SO}_{4}$ pekat dan $40 \mathrm{mg}$ resorsinol lalu dipanaskan perlahan lahan hingga warna hijau kotor, selanjutnya didinginkan dan ditambahkan $10 \mathrm{ml}$ air suling dan 
$\mathrm{NaOH} 10 \%$ berlebih. Bila terjadi warna hijau berfloresensi berarti sakarin positif dalam contoh.

Analisis Kualitatif Siklamat dengan uji pengendapan

Ditambahkan $10 \mathrm{ml}$ larutan $\mathrm{HCl}$ $10 \%$ ke dalam hasil saringan contoh kamudian ditambahkan $10 \mathrm{ml}$ larutan $\mathrm{BaCl}_{2} \quad 10 \%$. Biarkan 30 menit lalu saring lagi dengan kertas saring Whatman 42, kemudian ditambahkan $10 \mathrm{ml} \mathrm{NaNO}{ }_{2}$ 10\%. Dipanaskan di atas penangas air selama 30 menit. Bila timbul endapan putih dari $\mathrm{BaSO}_{4}$ berarti contoh mengandung siklamat.

\section{Analisis Kuantitatif}

Analisis Kuantitatif Sakarin dengan Spektrofotometri UV-Visible

\section{Pembuatan Larutan Baku}

Ditimbang dengan teliti $\pm 0,1$

gram sakarin kemudian dilarutkan dengan air suling. Di tambahkan $1 \mathrm{ml}$ $\mathrm{H}_{2} \mathrm{SO}_{4}$ pekat, lalu dipanaskan diatas penangas air selama 3 menit. Dibiarkan sampai dingin, lalu masukkan ke dalam labu ukur $100 \mathrm{ml}$. Dicukupkan volumenya sampai tanda (konsentrasi 1000 bpj).

\section{Penentuan Panjang Gelombang Maksimal}

Dibuat larutan standar 75 bpj dengan cara dipipet larutan baku $7,5 \mathrm{ml}$ ke dalam labu erlenmeyer ditambahkan
$50 \mathrm{mg}$ resolsinol dan $1 \mathrm{ml} \mathrm{H}_{2} \mathrm{SO}_{4}$ pekat kemudian dipanaskan di atas penangas air selama 3 menit. Dinginkan, dan masukkan ke dalam labu ukur $100 \mathrm{ml}$. Ditambahkan $10 \mathrm{ml}$ $\mathrm{NaOH}$ 0,1 $\mathrm{N}$ dan cukupkan volumenya sampai tanda garis. Diukur serapan larutan standar 75 bpj pada panjang gelombang maksimum.

\section{Pembuatan Kurva Baku}

Larutan standar 25 bpj, 50 bpj, 75 bpj, 100 bpj, dan 125 bpj diukur serapannya pada panjang gelombang $250 \mathrm{~nm}$.

\section{Penentuan Kadar Sakarin}

a. Ditimbang dengan teliti 10 gram contoh, lalu di encerkan dengan air suling $100 \mathrm{ml}$.

b. Ditambahkan arang aktif untuk menghilangkan warna lalu disaring sebanyak 3 kali .

c. Hasil saringan dipipet $10 \mathrm{ml}$ kedalam erlenmeyer lalu ditambahkan $50 \mathrm{mg}$ resolsinol dan $1 \mathrm{ml} \mathrm{H}_{2} \mathrm{SO}_{4}$ pekat.

d. Dipanaskan diatas penangas air selama 3 menit, kemudin didinginkan dan dimasukkan ke dalam labu ukur $100 \mathrm{ml}$.

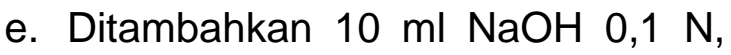
dan encerkan sampai tanda garis.

f. Diukur absorbannya pada alat spektrofotometri UV-Visibel pada panjang gelombang $250 \mathrm{~nm}$. 
Analisis Kuantitatif Siklamat Dengan Metode Gravimetri

Ditimbang dengan teliti \pm 15 gr contoh, kemudian diencerkan dengan air suling hingga $100 \mathrm{ml}$ (jika keruh, saring). Pada contoh ditambahkan 10 $\mathrm{ml} \mathrm{HCl}$ pekat dan $10 \mathrm{ml} \mathrm{BaCl}_{2} 10 \%$. Diaduk dan dibiarkan selama 30 menit. Jika terjadi endapan, disaring lalu cuci kertas saring dengan air. Filtrat dikumpulkan dan ditambah $10 \mathrm{ml}$ larutan $\mathrm{NaNO}_{2} 10 \%$ lalu diaduk. Tutup dengan kaca arloji dan dipanaskan diatas penangas air selama 2 jam, sambil kadang-kadang diaduk lalu dibiarkan ditempat hangat selama semalaman. Saring endapan kemudian di pindahkan endapan beserta kertas saring ke dalam krus yang sudah ditimbang. Dipijarkan hingga berat konstan, didinginkan dalam eksikator lalu timbang.

\section{HASIL PENELITIAN}

Berdasarkan hasil analisis kualitatif pada sampel Sari Buah Markisa menunjukkan bahwa semua sampel positif mengandung pemanis buatan sakarin dengan terbentuknya warna hijau berflouresensi dan pemanis buatan siklamat dengan adanya endapan putih.

Hasil analisis kuantitatif kandungan pemanis buatan sakarin dan siklamat dalam sampel Sari Buah Markisa dapat dilihat pada tabel di bawah ini :

Tabel 1. Kadar Rata-rata Pemanis Buatan Sakarin dan Siklamat

\begin{tabular}{ccc}
\hline Sampel & Sakarin & Siklamat \\
\hline $\mathrm{A}$ & $1021,1 \mathrm{mg} / \mathrm{kg}$ & $2,71 \mathrm{gr} / \mathrm{kg}$ \\
$\mathrm{B}$ & $4829,00 \mathrm{mg} / \mathrm{kg}$ & $2,88 \mathrm{gr} / \mathrm{kg}$ \\
$\mathrm{C}$ & $1761,91 \mathrm{mg} / \mathrm{kg}$ & $1,51 \mathrm{gr} / \mathrm{kg}$ \\
$\mathrm{D}$ & $629,59 \mathrm{mg} / \mathrm{kg}$ & $2,37 \mathrm{gr} / \mathrm{kg}$ \\
\hline
\end{tabular}

\section{PEMBAHASAN}

Penelitian ini dilakukan dengan menganalisis kandungan pemanis buatan sakarin dan siklamat dalam minuman sari buah markisa produksi makassar. Dimana penelitian ini bertujuan untuk menentukan kadar pemanis buatan sakarin dengan menggunakan spektrofotometri UVVisibel dan siklamat dengan menggunakan metode Gravimetri dan menetapkan kadar tersebut sesuai dengan aturan Departemen Kesehatan.

Pada umumnya dalam pembuatan minuman sari buah markisa tidak sepenuhnya menggunakan gula sebagai bahan pemanis melainkan sebagian menggunakan pemanis buatan seperti 
sakarin dan siklamat. Hal tersebut bertujuan untuk mencapai keuntungan , karena di samping harganya relatif murah juga mempunyai tingkat kemanisan yang jauh lebih tinggi dari pemanis alami.

Pada penelitian ini dilakukan analisis secara kualitatif dan kuantitatif sakarin dan siklamat dalam minuman sari buah markisa di mana sampel tersebut terdiri dari 4 macam merk yang berbeda diambil secara acak di beberapa supermaket di makassar.

Sampel yang akan dianalisis terlebih dahulu ditambahkan air suling kemudian di aduk hingga homogen hal ini bertujuan agar dapat mempermudah penyaringan dan selanjutnya siap untuk di analisis.

Pada sakarin dilakukan analisis kualitatif dengan uji resolsinol. Uji resolsinol pada analisis dilakukan dengan penambahan asam klorida dengan tujuan untuk mengubah garam sakarin dalam minuman sari buah markisa menjdi asam sakarin yang tidak larut dalam air. Selanjutnya diekstraksi dengan menggunakan eter sehingga asam sakarin dapat ditarik oleh eter.hasil ekstrak tersebut kemudian dibiarkan kering diudara terbuka agar diperoleh sakarin. Lalu dengan penambahan $\mathrm{H}_{2} \mathrm{SO}_{4}$ pekat terbentuk o-benzoatsulfonamida dan bereaksi dengan resolsinol menghasilkan senyawa yang berwarna hijau berflouresensi. Hasil analisis secara kualitatif dari keempat macam minuman sari buah markisa ini menunjukkan bahwa semua sampel yang dianalisis positif mengandung pemanis buatan sakarin. Pada siklamat dilakukan analisis kualitatif dengan uji pengendapan. Uji pengendapan pada analisis dilakukan dengan penambahan asam klorida dengan tujuan untuk mengubah garam siklamat dalam minuman sari buah markisa menjadi asam siklamat yang tidak larut dalam air. Selanjutnya di tambahkan $\mathrm{BaCl}_{2} \quad 10 \%$ dengan tujuan untuk membantu timbulnya endapan lalu di biarkan selama 30 menit dan kemudian disaring dengan kertas saring whatmen 42 . Selanjutnya ditambahkan lagi larutan $\mathrm{NaNO}_{2}$ dengan tujuan agar dapat bereaksi dengan suasana asam kuat sehingga dapat terbentuk larutan $\mathrm{BaSO}_{4}$. Kemudian di panaskan diatas penangas air selama 30 menit hingga timbul endapan putih. Hasil analisis secara kualitatif dari keempat macam minuman sari buah markisa ini menunjukkan bahwa semua sampel yang dianalisis positif mengandung pemanis buatan siklamat 
Pada pembuatan larutan baku ditambahkan asam sulfat pekat untuk mengubah garam sakarin dalam minuman Sari Buah Markisa menjadi asam sakarin menjadi larut.

Selanjutnya pada penentuan panjang gelombang maksimal dan penentuan kadar sakarin dilakukan dengan penambahan asam sulfat pekat sehingga terbentuk obenzoatsulfonamida dan bereaksi dengan resolsinol dan didinginkan dan setelah diencerkan dengan air suling ditambahkan dengan $\mathrm{NaOH}$ agar diperoleh basa yang sempurna. Selanjutnya diukur pada Spektofotometri UV-Visibel.

Dari ke empat merk sampel minuman Sari Buah Markisa semuanya positif mengandung pemanis buatan sakarin dan siklamat dimana pada pemanis buatan sakarin didapatkan kadar yang jauh melebihi batas yang telah di tetapkan oleh Menteri Kesehatan yaitu 50 - 300 $\mathrm{mg} / \mathrm{kg}$ bahan, sedangkan pada siklamat di dapat kadar yang tidak melampui batas yang telah di tetapkan oleh Menteri Kesehatan yaitu 500 mg - $3 \mathrm{gr} / \mathrm{kg}$ bahan.

\footnotetext{
Walaupun pemerintah telah mengeluarkan batasan untuk menggunakan pemanis buatan pada produk-produk minuman tetapi masih
}

banyak saja perusahaan yang menggunakan pemanis buatan tersebut tanpa memikirkan akibat yang di timbulkan jika di konsumsi dengan kadar yang berlebih yaitu adanya kanker kandung kemih. Hal ini kemungkinan di sebabkan oleh harganya yang relatif murah dan tingkat kemanisannya pun relatif lebih tinggi di banding dengan pemanis alami separti gula.

\section{KESIMPULAN}

Dari hasil penelitian dapat disimpulkan bahwa ke empat sampel minuman Sari Buah Markisa positif mengandung pemanis buatan sakarin dan siklamat dengan kadar rata-rata untuk sakarin dalam minuman sari buah markisa melebihi batas yang ditetapkan oleh Menkes dan siklamat memenuhi syarat yang diperbolehkan oleh Menkes.

\section{DAFTAR PUSTAKA}

Almatsier, S., 2003, Prinsip Dasar IImu Gizi, PT. Gramedia Pustaka Umum, Jakarta, Hal. 48.

Apriyantono, dkk. 1989, Analisis Pangan, Departemen Pendidikan dan Kebudayaan Direktorat Jenderal Pendidikan Tinggi, Pusat Antar Universitas Pangan dan Gizi, Institut Pertanian Bogor, Bogor.

Ashari, S., 1995. Holtikultura Aspek Budidaya, Penerbit Universitas 
Indonesia, Jakarta, Hal.346349.

Balai Penelitian Pengembangan Industri, 1995, Minuman Sari Buah, Standardisasi Nasional Indonesia, SNI 01 - 3719 1995, Makassar.

Bassett J., Denney, R.C., Jeffery, G.H., Mendham, J., 1994. Vogel : Kimia Analisis Kuantitatif Anorganik. Edisi 4, Penerbit Buku Kedokteran Jakarta, Hal. $472-811$.

Cahyadi, W. 2006, Kajian dan Analisis Bahan Tambahan Pangan, Edisi Pertama, Jakarta, Bumi Aksara.

Day, R.A., Underwood, A.L., 1963, Analisis Kimia Kuantitatif, Edisi V, Alih Bahasa Setiono, L., Erlangga, Jakarta. Hal. 472

Departemen Perindustrian \& Perdagangan., 1994, Mutu dan Cara Uji Makanan yang Mengandung Pemanis Buatan, Badan Penelitian Pengembangan Perindustrian. Standar Nasional Indonesia, SNI No. 2893/94. Hal. 4.

Menteri Kesehatan, 1988, Peraturan menteri Kesehatan Tentang Bahan Tambahan Makanan, DepKes RI, Jakarta.

Mulja, M, Suharman, 1995, Analisis Instrumental,

Penerbit
Airlangga University Press, Surabaya, Hal.19-41, 48-58

Rismunandar,1986,

Mengenal Tanaman Buah-buahan, CV. Sinar Baru, Bandung, Hal. 3-8

Rismana, E., Paryanto I. 2002, Beberapa Bahan Pemanis Alternatif yang Aman, Jakarta, Kompas Cyber Media.

Rukmana, R., 2003, Usaha Tani Markisa, Kanisius, Yogyakarta. 9-11.

Trenggono, dkk, 1990, Bahan Tambahan Pangan (Food Additivies)., Penerbit Pusat Antar Universitas Pangan dan Gizi, Universitas Gajah Mada, Yogyakarta, Hal. 141.

Syafri , 1997/1998, Identifikasi Pemanis Buatan (Sakarin, Siklamat, Dulsin) Dalam Makanan dan Minuman Secara Spektrofotometer, Buletin Litbung Industri, No.2, Vol.15, Hal. 13-14.

Sastrohamidjojo, $\quad$ H., $\quad 1985$, Spectroscopy, Liberty, Yogyakarta. Hal. 382.

Verheij, E.W.M., dan Coronel, R.E., 1997. Buah-buahan yang Dapat Dimakan. Penerbit PT. Gramedia Pustaka Utama, Jakarta.

Winarno F.G., 1997. Kimia Pangan dan Gizi. Jakarta, Penerbit PT Gramedia Pustaka Utama. 